\title{
Possible olfactory transduction of radiation-induced aversion'
}

WALTER H. RIEGE, University of California, Berkeley, Cal. 94720

After whole-body $X$ irradiation (280 kvp, $4.8 \mathrm{~mA}, 48 \mathrm{r}$ ) for $1 / 2$ $h$, rats showed an ostensible aversion to previously preferred Saccharin drinking even when they had been anesthetized during the exposure. The sequelae of low-dose irradiation, however, were not observed for eight days of testing in rats that had their nasal passages occluded with paraffin and breathed through oral-tracheal tubes while they were anesthetized and irradiated. Possibly, the nasal occlusions and the short-lasting hypoxia subdued the radiation effect at the olfactory epithelium, so that the trace-conditioned aversion failed to develop.

The presence of an intact olfactory system appears to be important for the rat's detection of ionizing radiation. Yet little is certain about the extent to which the sensitivity of the olfactory system results from direct or indirect receptor stimulation or from radiation effects upon the bulbar neuropile. X-rays may act as "distributive stimulus" through non-injurious effects on ongoing central synaptic activity, which mediate detection through neuronal and humoral mechanisms (Kimeldorf \& Hunt, 1965). Other investigators propose (Brust-Carmona, Kasprzak, \& Gasteiger, 1966) detection of low-level radiation may be initiated by very small quantities of substances, transiently produced at the site of the olfactory membrane.

In an attempt to localize the radiation transducer, Garcia and co-workers (1964) observed that the head region containing the olfactory bulbs was much more sensitive to a small-diameter collimated beam of X-rays than were more caudal parts of the rat's head. Subsequent experiments by Hull and others (1965) showed that the ablation of the olfactory bulbs greatly diminished the proportion of sleeping rats which showed EEG desynchronization to low-rate X-ray exposures. Olfactory ablation, moreover, was found (Dinc \& Smith, 1966) to impair the radiation-induced aversion to Saccharin drinking of rats. Incomplete ablation of the bulbs, sham operation, or frontal lobe lesions did not produce the overriding of the conditioned aversion.

Indirect action of X-ray stimulation were not only suggested by the finding that Saccharin aversions have been induced by abdominal exposures with the head shielded (Garcia \& Kimeldorf, $1960)$ but also by the indication that relatively small amounts of ozone (4-5 mg/h) may mask an X-ray produced odorant (Helling \& Gasteiger, 1967). To test for the similarity of X-rays and ozone as olfactory stimuli, the investigators conditioned rats to stop licking to avoid shock when either ozone or ethyl butyrate (pineapple odor) for 10-sec periods were introduced into their nasal cavities through cannulae chronically implanted into their frontal sinuses. Transfer of the suppression response to X-rays was tested by interspersing randomly 10 -sec irradiation periods, without shock, among the odor stimulation periods, with shock. Ozoneconditioned animals suppressed licking during X-ray exposures, while the rats, conditioned to pineapple odor, did not.

The implication that rats "smell" the presence of low-level $\mathrm{X}$-rays, however, is not sufficiently borne out. Furthermore, $\mathrm{X}$-rays act not only as discriminative but also as unconditional aversive stimulation. It is with the latter function that the transducer stage is unclear. Can a radiation-induced Saccharin aversion develop in rats if their olfactory epithelia are excluded from stimulation?

\section{METHOD}

Twenty-four naive Sprague-Dawley rats, not more than 120 days old, were gradually adapted to drink Saccharin-sweetened water over a 1-week period. The rats were then randomly assigned to three groups of eight subjects (Ss) each. Each rat was housed in a $15 \times 25 \times 30 \mathrm{~cm}$ polyethylene cage with wire mesh top, two of the groups in the radiation room and the other eight Ss in an adjacent shielded room. Thereafter, all animals were fluid deprived for $23 \frac{1 / 2}{2}$ every day for two weeks.
During the daily $1 / 2-h$ drinking period each rat had access to two drinking bottles. Tap water and a $0.1 \%$ Saccharin solution were presented to each animal in $24 \times 150 \mathrm{~mm}$ Kimax test tubes. These were fitted with a rubber stopper and a $7-\mathrm{cm}$ glass tubing which passed through the stopper forming a spout. A piece of galvanized wire was inserted in the glass tubing the full length in order to permit the fluid to flow freely. Before and after each drinking period the bottles were weighed with a torsion balance to the nearest $0.1 \mathrm{~g}$ and the daily differences were taken to be equal to the amount of fluids consumed.

Irradiation procedures started on the fifth day after onset of deprivation, when Saccharin preferences had stabilized for three days above an $80 \%$ level. On the irradiation day, all rats were weighed and anesthetized with an i.p. injection of Myotal (0.5 $\mathrm{mg} / \mathrm{kg}$ ) immediately following the drinking period. With deep anesthesia, when no more eyeblink reflex was registered, in each of eight rats a $5-\mathrm{cm}$ piece of intramedic tubing (PE 320, inner diameter $2.7 \mathrm{~mm}$ ) was inserted into the trachea through the rat's mouth. In addition, the nasal passages of these eight rats (Group IRR-AN-OCC) were occluded. Several layers of melted paraffin were molded over the snout and nostrils to a thickness of approximately $5 \mathrm{~mm}$. The rats were thus returned to their cages with their heads pointing to the X-ray source. The second group of eight anesthetized rats (Group IRR-AN) stayed in their cages in the radiation room, while the third group (Group Control-AN) was subjected to anesthesia in the shielded room.

Irradiation started not later than $30 \mathrm{~min}$ after the last animal had been injected and lasted for $30 \mathrm{~min}$. During this period, exposure to hard X-rays $(280 \mathrm{kvp}, 4.8 \mathrm{~mA}, 1.6 \mathrm{r} / \mathrm{min}$, with a filtration of $0.5 \mathrm{~mm} \mathrm{Al}$ and $0.5 \mathrm{~mm} \mathrm{Cu}$ added to the inherent filter of $4.25 \mathrm{~mm} \mathrm{Al}$ ) from a transportable unit (Eresco 300) was permitted. The target-to-source distance was $200 \mathrm{~cm}$. An accumulated dose of $48 \mathrm{r}$ was measured as the mean of the readings of two Victoreen dosimeters placed at target distance. Ten minutes after the irradiation offset, the paraffin occlusions were peeled and scraped off the rats' snouts and intratracheal tubes were removed. The effect of the anesthetic continued to last for another hour after exposure offset. Saccharin drinking was measured with the two-bottle choice test and the $231 / 2-h$ fluid deprivation schedule on the following day and for eight consecutive days.

\section{RESULTS AND DISCUSSION}

Following the traditional method (Garcia \& Kimeldorf, 1960), a Saccharin preference score in per cent was calculated for each rat every day by dividing the volume of Saccharin solution ingested by that of the total fluid consumed. The course of the mean group scores, as shown in Fig. 1, sensitively reflected the motivational fluctuations in drinking during the experiment. Again it was found that an ostensible aversion to the previously preferred Saccharin solution developed in the anesthetized and irradiated rats (Group IRR-AN) within $24 \mathrm{~h}$ after exposure. The aversion lasted for at least eight days with no evidence for its extinction.

In contrast, the sequelae of whole-body irradiation became not apparent in rats that had their nasal passages occluded (Group IRR-AN-OCC). These animals showed only a slight diminution (11\%) in their Saccharin preferences during the first two post-exposure days, but they were not statistically distinguishable from the preference level of non-irradiated rats (Group CONTROL-AN). In their drinking choices, the occluded and the control rats apparently were little scathed by the effect of anesthesia. After exposure, their preferences deviated not significantly from their preexposure level.

An analysis of variance of daily preferences among the groups indicated that the effects of Group Condition $(F=18.273$, $\mathrm{df}=2 / 15)$, of Pre- and Post-Exposure Days $(\mathrm{F}=17.480$, $\mathrm{df}=10 / 150)$, and their interaction $(F=8.196, \mathrm{df}=20 / 150)$ were significant contributors to preference differences $(p<.01)$. Found to be responsible for the divergence were the low Saccharin 


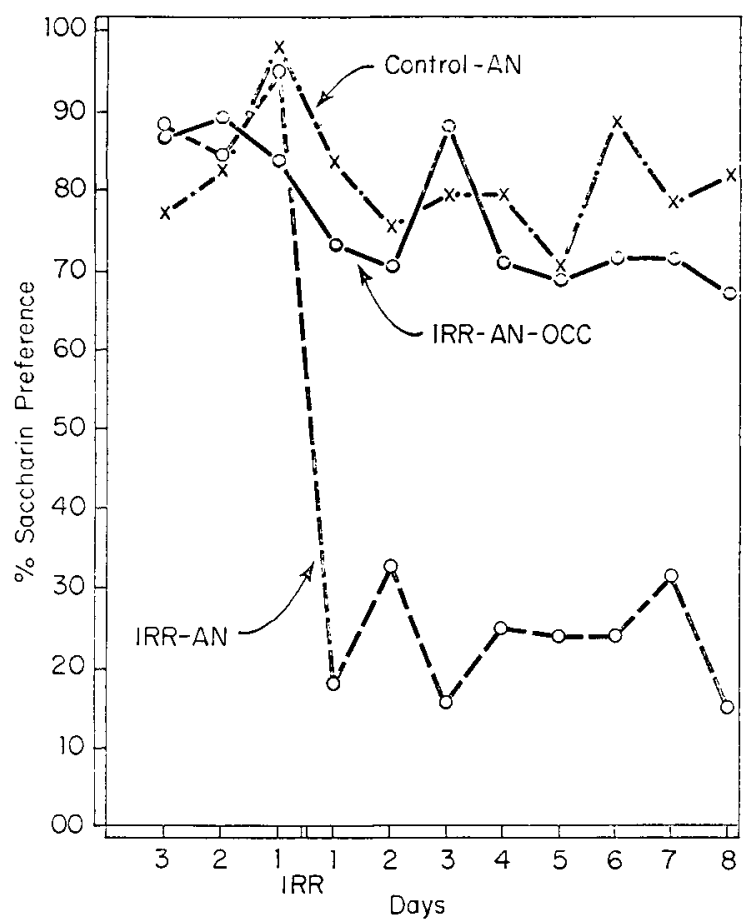

Fig. 1. Per cent saccharin consumption of total fluid intake of three groups of rats, anesthetized during $1 / 2 \mathrm{~h}$ exposure to $48 \mathrm{R} \times$ rays (Group IRR-AN) and nostrils occluded (Group IRR-AN-OCC) or sham-irradiated (Group CONTROL-AN).

preferences of rats in Group IRR-AN after irradiation, when mean pre- and post-exposure scores were compared a posteriori with the method of Newman-Keul (Winer, 1962). Two rats died after exposure and occlusion and were excluded from the results.

The Saccharin taste was an adequate conditional stimulus for the noxious X-irradiation. Even when exposed to X-rays under barbiturate anesthesia, rats developed an aversion to Saccharin when drinking occurred shortly before irradiation and anesthesia. Similarly, Hunt \& Kimeldorf (1966) observed radiation-induced aversion in rats that had been offered Saccharin solution after irradiation and anesthesia. The motivational shift always was not associated with an aversion to drinking of fluids per se; irradiated rats merely drank less of the Saccharin solution than they had before.

of interest was particularly the present finding that after irradiation no Saccharin aversion developed in the occluded rats during eight days of preference testing. Since the nasal passages had been temporarily made non-functional, it appears that olfactory receptors would be one of the possible radiation transducers. The effect of a light hypoxia, when occluded rats breathed through oral-tracheal tubes while exposed to X-rays, may have been additive to prevent the decline in Saccharin preferences. A delayed or depth effect of X-rays, mediated through the olfactory bulbs, did not seem to be active. If a humoral agent acted independently from the olfactory detection system, aversion should have developed later in the occluded rats since abdominal areas were said (Garcia \& Kimeldorf, 1960) to be sensitive for inducing the Saccharin aversion.

There is some evidence that X-rays can alter the activity of olfactory bulb neurons by an effect on olfactory receptors (Cooper, Kimeldorf, \& McCorley, 1966). Perfusing nitrogen or argon through the nasal passages of anesthetized and tracheotomized rats modified or suppressed the olfactory-neuron unit activity during $\mathrm{X}$-ray exposures, but perfusion with air or oxygen could not do so. It was suggested that olfactory neuron responses to irradiation were linked with receptor stimulation, but that it was more important that oxygen was in solution in the epithelial mucus than what gas was in the nasal cavities.

The same mechanism may help to understand the present results. Low-level X-ray stimulation may become transduced by the olfactory system when nasal airflow was unhindered. With nasal occlusions, however, and perhaps the temporary effect of hypoxia, the radiation impact at the receptor site was prevented or subdued so that the trace-conditioned aversion failed to develop. REFERENCES

BRUST-CARMONA, H., KASPRZAK, H., \& GASTEIGER, E. L. Role of the olfactory bulbs in X-ray detection. Radiation Research, 1966, 29, 354-361. COOPER, G. P., KIMELDORF, D. J., \& McCORLEY, G. C. The effects of various gases in the nasal cavities of rats on the response of olfactory bulb neurons to X irradiation. Radiation Research, 1966, 29, 395-402.

DINC, H. I., \& SMITH, J. C. Role of the olfactory bulb in the detection of ionizing radiation by the rat. Physiology \& Behavior, 1966, 1, 139-144.

GARCIA, J., \& KIMELDORF, D. J. Some factors which influence radiationconditioned behavior of rats. Radiation Research, 1960, 12, 719.727.

GARCIA, J., BUCHWALD, N. A., FEDER, B. H., KOELLING, R. A., \& TEDROW, L. Sensitivity of the head to $X$ ray. Science, 1964, 144 $1470-1472$.

HELLING, S. A., \& GASTEIGER, E. L. Behavioral evidence that ozone mediates X-ray detection. Radiation Research, 1967, 31, 658-659.

HULL, C. D., GARCIA, J., BUCHWALD, N. A., DUBROWSKY, B., \& FEDER, B. H. Role of the olfactory system in arousal to $X$ ray. Nature, $1965,137,857.859$.

HUNT, E. L., \& KIMELDORF, D. J. The humoral factor in radiation-induced motivation. Radiation Research, 1966, 30, 404-419.

KIMELDORF, D. J., \& HUNT, E. L. Ionizing radiation: Neural function and behavior. New York: Academic Press, 1965. Pp. 284-289.

WINER, B. J. Statistical principles in experimental design. New York: McGraw-Hill, 1962. Pp. 80-86.

\section{NOTE}

1. This investigation was supported in part by a NASA Traineeship and was made possible through the use of the facilities of the Animal Behavicr Laboratory, Department of Psychology, University of Georgia, Athens, Georgia. 